\title{
Politics and Policy Outcomes on Children Affected by HIV/AIDS in Africa
}

\author{
Per Strand, Mary Kinney and Robert Mattes'
}

\begin{abstract}
1 Introduction
Global agencies working for children affected by AIDS have recently reported some progress (UNAIDS 2008). Year by year, more HIV-positive pregnant women receive medication to avoid infecting their unborn babies, increasing numbers of children in late stages of HIV infection receive antiretroviral treatment (ART), and a higher proportion of affected children enjoy some form of social protection and schooling. However, while all this is good news, countries still fail to provide basic services to the majority of orphans and vulnerable children (OVC) in the context of AIDS. Clearly, all stakeholders need to do more to protect children from the effects of AIDS. But how can this be done? A dominant discourse suggests that governance and politics can provide leverage to a more effective response.
\end{abstract}

Advice from global agencies on how countries should respond to AIDS is based on the central assumption that whatever the level of structural disadvantage and severity of the epidemic, countries can fight AIDS (more) effectively if they get the politics right. There have been repeated calls for better 'leadership'. These recommendations have an institutional dimension that is summarised in the 'Three Ones': one HIV/AIDS action framework, one national AIDS coordinating authority, and one monitoring and evaluation system (UNAIDS 2004). However, these institutions and processes should also be based in and give effect to more normative politics of democracy; responses should mainstream human rights, and allow for participation and accountability (UNAIDS 2006a). While the institutional blueprint is meant to make governance more effective, the central motivation for the normative dimension is to ensure HIV-positive people of protection against discrimination and access to policymaking on AIDS. But the hypothesis that politics can make a difference is relevant also beyond the specifics of the AIDS response. More general theories of democracy and governance suggest that countries that are more democratic and countries that have better governance will respond more effectively to societal challenges, also in a development context (Halperin et al. 2005; Goetz and Jenkins 2004; Sen 1999; UNDP 2002).

This reasoning leads us to the central question for this research: are countries with better AIDS governance, with better governance generally and with higher quality democracy more effective in responding to the needs of children affected by AIDS? Or in a different formulation, are any elements of governance or democracy determinants of the effectiveness of such responses? If we can identify any such political factors we have contributed to the explanation of why some countries perform better in their responses to AIDS, but the results may also hold clues for more effective advocacy strategies.

\footnotetext{
Our research is guided by four contributions in the literature that seek to explain variations in country responses to AIDS through the same methodology that we will apply here, statistical analysis of data from a large number of countries. The research by Nicoli Nattrass (2006) seeks to explain variations in Highly Active Antiretroviral Therapy (HARRT)
} 
coverage on the basis of data from 77 transitional and developing countries. She includes two political variables in a larger set of variables on economic, structural and regional effects. In terms of the political variables, her results show that quality of the electoral process has no impact but that established democracies have better coverage. Mary Kinney's research (2007) tests the effect of foreign aid on ART coverage in sub-Saharan Africa. The research controls for the political variables identified by Nattrass, but it also includes data on the quality of governance and levels of democracy. With regard to politics, the research shows that better governance is a determinant of higher ART coverage.

The research by Evan Lieberman (2007) tests whether the coverage of ART across 85 developing countries is determined in part by countries' degree of ethnic fractionalisation, a factor that is assumed to reflect the degree to which the provision of public goods is hampered by the politics of neopatrimonialism. In terms of political factors, he finds that both ethnic fractionalisation and government effectiveness determine ART. The research by Jacob Bor (2007), finally, argues an explanation for the quality of governments' responses to AIDS, as measured by the 'political support' score in the AIDS Program Effort Index with data on 53 developing countries (POLICY Project 2003). In terms of political factors, he concludes that electoral accountability has a statistically significant negative effect on the quality of the response, suggesting that competitive democratic elections are a disincentive for a strong government action. Instead of elections, he finds that the level of press freedom has a positive effect.

These four different analyses reach somewhat different results because they use different data to capture abstract political concepts and because they include different countries in their analyses. Despite these differences, it is clear that political variables are relevant and sometimes central to the explanatory argument. Compared to the four analyses above, our research here is more explorative. Instead of generating a 'best model' explanation for a particular outcome - a model that may or may not include a political variable - we will test the relevance of a number of political variables for explaining a number of different policy outcomes, as will become clear in the section below. Our research is based on data from 42 of the 44 countries in sub-Saharan Africa (excluding only Liberia and Equatorial Guinea), the sub-continent which is worst affected by the global AIDS pandemic and where the needs of children affected by AIDS present governments with particular challenges.

\section{The data set}

As we will introduce and discuss more technical aspects of our research in the next two sections we need to say a few words on our chosen style of presentation. This article is aimed at as broad a readership as possible. Our prime purpose is to communicate our rationale for asking the questions, our methodology for finding answers (in broad terms), and the substance and implications of our findings. We will therefore keep the statistical information at a minimum so as not to lose readers who are unfamiliar with statistical notations and discussions. An expanded version of the article which includes all the required statistical details of our analysis is available online. ${ }^{1}$

\subsection{Policy outcomes}

Three of our variables on policy outcomes are both AIDS-related and child-specific: the coverage of ART for children, the coverage of ART for the prevention of mother-to-child-transmission (PMTCT), and the ratio of school enrolment between double orphans and non-orphans (UNAIDS 2007). To these, we add the 'policy score' that countries achieved in the OVC Index (Monasch et al. 2007, see further below) even though it captures the quality of policy processes and content rather than its outcome.

The variables above are our prime focus. However, in order to interpret them correctly we need to compare them with policy outcomes that are not related to AIDS and not directed at children. One such outcome is the coverage of ART for all in need of antiretrovirals (ARVs) (UNAIDS 2006b). This comparison will indicate whether other political dynamics are at play when the beneficiaries of the policy are more numerous and eligible to vote. We also have data on four policy outcomes that are not directly linked to AIDS: the percentage of people who have access to water, and to sanitation; the percentage of children who go to school; and finally the coverage of measles immunisation for one-yearold children (UNDP 2006). This comparison will tell us if AIDS-related policy issues have a particular political logic, perhaps due to the stigma attached to AIDS. 
Table 1 Correlating political and policy outcome variables

\begin{tabular}{|c|c|c|c|c|c|c|c|}
\hline \multirow[t]{2}{*}{ Explanatory variables } & \multicolumn{7}{|c|}{ Dependent variables } \\
\hline & $\begin{array}{l}\text { OVC ART } \\
(\log )\end{array}$ & $\begin{array}{l}\text { РMTCT } \\
(\log )\end{array}$ & $\begin{array}{l}\text { ART } \\
(\log )\end{array}$ & $\begin{array}{l}\text { Water } \\
(\log )\end{array}$ & $\begin{array}{l}\text { Sanitation } \\
(\log )\end{array}$ & School & $\begin{array}{l}\text { Immunisation } \\
(\log )\end{array}$ \\
\hline \multicolumn{8}{|l|}{ AIDS governance } \\
\hline API total score & $0.430^{*}$ & 0.224 & $0.430^{* *}$ & & & & \\
\hline $\begin{array}{l}\text { API care and } \\
\text { treatment services }\end{array}$ & $0.502^{* * *}$ & 0.290 & $0.558^{* * *}$ & & & & \\
\hline OVC Index total score & 0.180 & $0.467^{*}$ & 0.186 & & & & \\
\hline $\begin{array}{l}\text { OVC Index national } \\
\text { action plans }\end{array}$ & $0.369^{*}$ & $0.408^{* *}$ & 0.121 & & & & \\
\hline \multicolumn{8}{|l|}{ General governance } \\
\hline Governance index & $0.540^{* * *}$ & $0.371^{* *}$ & $0.505^{* * *}$ & $0.398^{* * *}$ & $0.264^{* *}$ & $0.607^{* *}$ & $0.424^{* * *}$ \\
\hline \multicolumn{8}{|l|}{ Democracy } \\
\hline $\begin{array}{l}\text { Combined freedom } \\
\text { score }\end{array}$ & $0.323^{*}$ & 0.106 & $0.272^{*}$ & $0.282^{*}$ & $0.298^{*}$ & $0.415^{* *}$ & $0.376^{* *}$ \\
\hline $\begin{array}{l}\text { Voice and } \\
\text { accountability }\end{array}$ & $0.395^{* *}$ & $0.298^{*}$ & $0.337^{* *}$ & $0.391^{* *}$ & $0.351^{* *}$ & $0.536^{* * *}$ & $0.387^{* *}$ \\
\hline \multicolumn{8}{|l|}{ Press freedom } \\
\hline Press freedom score & 0.307 & 0.110 & 0.300 & 0.251 & 0.286 & $0.426^{* *}$ & $0.380^{*}$ \\
\hline
\end{tabular}

Correlation coefficients (Pearson $r$ ) between dependent and explanatory variables. ${ }^{*} p<0.1,{ }^{* *} p<0.05,{ }^{* * *} p<0.01$. API: AIDS Program Effort Index (POLICY Project 2003); OVC Index: OVC Policy and Planning Effort Index from 2004 (Monasch et al. 2007).

\subsection{Political variables}

The ten political variables we will be working with can be grouped into five sets: general governance, democracy, press freedom, political competitiveness and AIDS governance. By general governance we mean the quality of institutions and effectiveness of the political, bureaucratic and judicial processes of the state. On the basis of data from the World Bank, we created an index out of four aspects of governance that are strongly associated (Kauffman et al. 2004). We use three variables to capture different aspects of the quality and strength of democracy. Also from the World Bank, the variable 'voice and accountability' captures the electoral dimension of democracy. In order to capture the extent to which rights and freedoms are respected we created a 'combined freedom score' on the basis of data from Freedom House on civil and political rights. ${ }^{2}$ The third alternative measurement of democracy is generated by the Polity Project. ${ }^{3}$ The degree of press freedom is reported by Freedom House, and the level of competitiveness in the political system is measured by the parliamentary strength of the largest opposition party (Lindberg 2006).

Our final set of political variables are all elements of 'AIDS governance', a notion that refers to the different institutions and processes that countries have adopted for the specific purpose of responding effectively to HIV/AIDS (Strand 2007). We have two sets of data on this form of governance, the AIDS Program Effort Index (POLICY Project 2003) and the OVC Policy and Planning Effort Index from 2004 (Monasch et al. 2007). We will refer to them as the 'API' and the 'OVC Index', respectively. Both are based on surveys filled out by key informants and stakeholders working in the field of HIV/AIDS in the different countries. The two surveys identify a number of elements to the country responses, each of which are assessed qualitatively and given a score - the API has ten such elements and the OVC Index has eight. The mean of those scores is referred to as the 'total score' for each country. Each survey only covers a subset of the 42 countries in our dataset. 
Table 2 Causal effect of political factors on policy outcomes

\begin{tabular}{lllll}
\hline $\begin{array}{l}\text { Explanatory variables } \\
\text { OVC ART (log) }\end{array}$ & ART (log) & School & Immunisation (log) \\
\hline $\begin{array}{l}\text { AIDS governance } \\
\text { API total score }\end{array}$ & $0.344^{* *}(0.007)$ & $0.316(0.007)$ & & \\
API care and treatment & $0.308^{* *}(0.005)$ & $0.489^{* *}(0.004)$ & & \\
$\begin{array}{l}\text { General governance } \\
\text { Governance index }\end{array}$ & $0.313^{*}(0.112)$ & $0.324^{*}(0.094)$ & $0.439^{* *}(2.692)$ & $0.411^{* *}(0.027)$ \\
$\begin{array}{l}\text { Democracy } \\
\text { Combined freedom score }\end{array}$ & $0.209(0.030)$ & $0.176(0.025)$ & $0.262^{*}(0.725)$ & $0.334^{* *}(0.007)$ \\
$\begin{array}{l}\text { Voice and accountability } \\
\text { Co. }\end{array}$ & $0.155(0.141)$ & $0.178(0.114)$ & $0.311^{*}(3.308)$ & $0.322^{*}(0.033)$ \\
\hline
\end{tabular}

Standardised regression coefficients (B) with standard errors in parentheses. ${ }^{*} p<0.1,{ }^{* *} p<0.05,{ }^{* * *} p<0.01$. API: AIDS Program Effort Index (POLICY Project 2003).

Further, since data on one or more dependent variables is missing for some countries, our analysis of the API includes 27-9 countries and the OVC Index includes 34-6 countries, depending on which variable is analysed.

As all of these political variables are based on a combination of fact and judgement - much like politics itself - their validity should be assessed carefully. The more general variables are commonly used for research purposes and are broadly accepted as the best available measures of the complex notions they try to capture. The data from the API and the OVC Index are potentially more problematic as the process of deciding on the scores was vulnerable to bias of a nature and degree that is not reported.

\section{Identifying association (correlation) and causation}

In the initial set of analyses we establish which political variables are linked statistically to one or more of the outcome variables. While many variables are correlated as would have been expected, some are not. The competitiveness of the political system and the Polity Project measure of democracy have no statistically significant correlations to any of the outcome variables, and no political variables are linked to the schooling ratio between orphans and non-orphans or to the OVC Index 'policy score'. These variables will therefore be excluded from further analysis. Of the AIDS governance variables, we report the 'total score' and the individual variable with the strongest link to one or more of the three AIDS-related dependent variables (Table 1).

Two results are worth highlighting at this stage. All associations are positive, which means that higher scores on the political variables are linked to better coverage and supply of policy outcomes, albeit many links are weak and some are not statistically significant. Second, several of the AIDS governance variables that would have been expected to be linked to better policy outcomes, given the weight granted to them in policy advocacy, had no such effect. Most notably, the API variables 'political support' and 'human rights' had no statistically significant link to policy outcomes. We shall return to those two $\mathrm{API}$ variables further below.

The second step in the analysis is to test whether any of these correlations qualify as causal links between the political and policy outcome variables. This is done through a set of regression analyses that include a number of control variables. These control variables are, potentially, alternative explanations for the links between political and outcome variables. They are included to ensure that they are not the actual cause of the causal effect on the policy outcome variable that we otherwise, mistakenly, would have attributed to political variables. The two control variables that will be used in all regressions are GDP per capita in 2003, and 'ethnic fractionalisation'. The first variable captures what financial resources were available to government and it is also generally accepted as a proxy for overall state capacity. The second variable is included to 
control for Lieberman's results, using the variable 'PREG' created by Dan Posner (2004). In the regressions on the AIDS-related policy outcomes we also control for the severity of the epidemic with data on HIV prevalence in 2005, and the level of foreign aid that was earmarked for AIDS that countries received in 2003-4 (Kinney 2007). In analyses of non-AIDS-related policy outcomes we use the total overseas development aid per capita (in 2003) to control for external funding. For technical reasons, the regression analyses included only one political variable at a time. The two exceptions to this will be noted below.

The results of the regression analyses are summarised in Table 2. In order to simplify the presentation, we have included only the combination of political and policy outcome variables where one or more causal links were statistically significant. $A$ number of variables fall away from the analysis as the correlation we identified above were not sufficiently strong to survive the regression analysis. We note in particular that no political variables could contribute to the explanation of the variation in the coverage of PMTCT. This is probably mainly because Namibia and South Africa - countries with relatively high scores on governance and democracy - had under achieved, whereas Swaziland, a country with poor scores on both governance and democracy, had reached the second highest level of coverage.

Starting with the AIDS governance variables, it was to be expected that the API variable 'care and treatment' has a causal effect on both outcome variables since it measures countries' coverage of a range of treatments and support services for AIDS. This tautology invalidates any actual explanatory power of this variable, but we shall nevertheless return to it further below. The API 'total score' has some causal effect on 'OVC ART', a finding which supports the argument that the effective adoption of the prevailing policy recommendations leads to a better response in terms of actual outcomes.

Of all the political variables it is the governance index that is most effective with a causal effect on all four of the remaining outcome variables. In the two regressions on the AIDS-related variables, governance is the only significant variable, both models explaining about a third of the variation (adjusted $R^{2}$ ). We can conclude that the comparison between AIDS-related outcomes benefiting children and those aimed at adults showed no real differences. Both of them are explained to some extent by governance, but neither of them is affected by democracy, either in terms of freedom or electoral accountability. It is instead the comparison between outcomes that are AIDSrelated and those that are not that have produced some interesting results. Although the causal effect is not very strong, it is clear that the levels of school enrolment as well as the coverage of measles immunisation are both determined to some extent by governance, but also by the quality of democracy, both in terms of its electoral dimension and the existence and respect for civil and political freedoms. ${ }^{4}$ These are the only two outcome variables that are affected by the democratic variables. This result is particularly interesting since these policies are directed towards children, but unlike AIDS, the needs that motivate them are not stigmatised. The demand for both these outcomes would be the same across all countries included in our analysis. Children need schooling and immunisation equally as much in Botswana, Angola and Tanzania. And, we can assume, their parents want both for their children equally badly in all countries. And yet, countries deliver unevenly. The larger part of this variation ${ }^{4}$ is explained by the level of domestically generated wealth per capita in relation to schooling, and the level of foreign aid in relation to immunisation. But we also learn that more children go to school and receive immunisation in countries where their parents' votes make more of a difference and where they can claim their political rights and freedoms. We will comment further on this finding in the concluding section.

\subsection{A plausible causal pathway}

The last exploratory step of the statistical analysis will add some complexity by testing whether we can trace some additional indirect effect from political variables on AIDS policy outcomes. The only subset of our dataset that allows for this analysis is the 29 countries that are included in the API survey. The two relevant $\mathrm{API}$ variables measure the degree to which the response has 'political support' from the highest level and the degree to which human rights are mainstreamed into the response. We learnt above that neither had a direct link to any of the outcome variables. But could it be that strong political support and a response that really respects human rights affect outcomes more indirectly through another variable? And if this is the case, are there any 
Figure 1 Modelling a plausible causal pathway

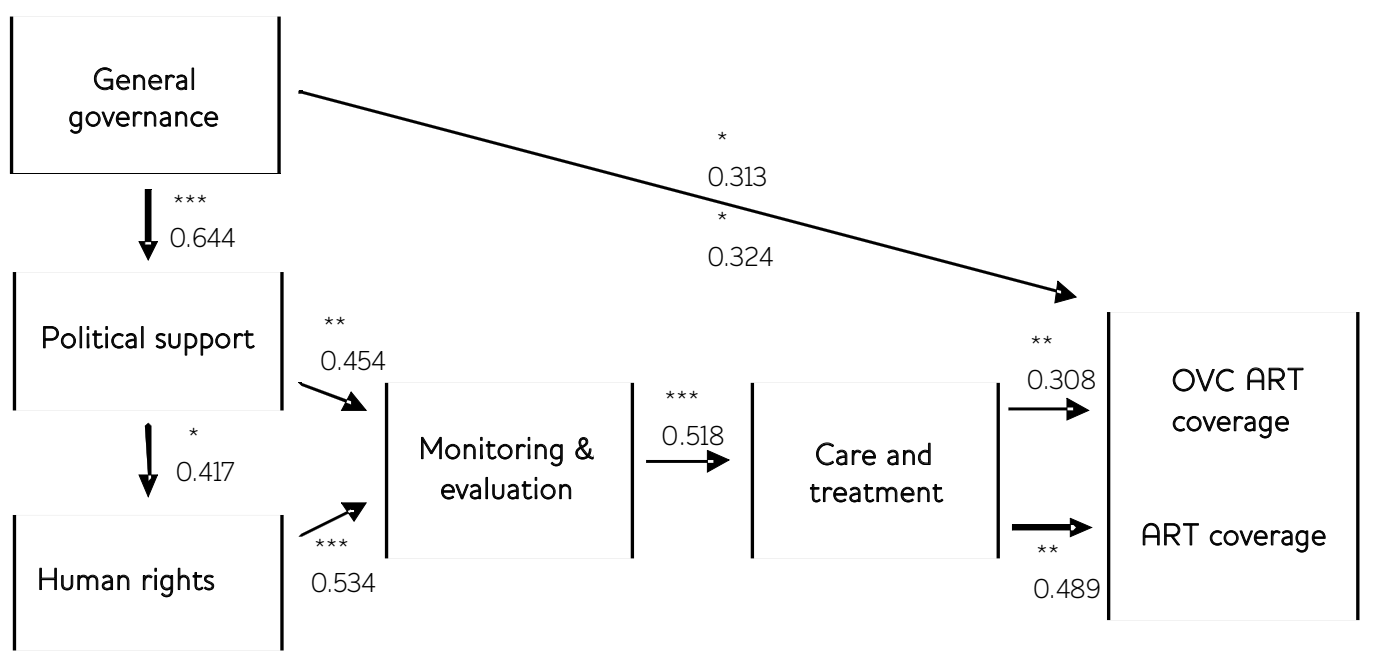

Standardised regression coefficients: ${ }^{*} p<0.1,{ }^{* *} p<0.05,{ }^{* * *} p<0.01$.

indications that the level of political support and the quality of human rights mainstreaming depend, in turn, on political factors that could be leveraged for a stronger overall response?

Our way of exploring these complexities is through a set of regression analyses, using the same control variables as above with the addition of the general governance index. We shall try to trace any such effects 'backwards' in the causal pathway, starting with an explanation of why some countries have better quality care and treatment programmes (Figure 1). We find that this can in parts be explained by the quality of countries' monitoring and evaluation (M\&E) of the AIDS response. This would make sense, as it is only through effective M\&E that any problems with the care and treatment programmes can be identified, analysed and rectified continuously. But this begs the question why some countries have more effective $M \& E$, and this is where the two political variables enter the picture. In a regression that included both 'political support' and 'human rights', both variables proved to have a causal effect on the quality of M\&E. Our suggested interpretations for how those causal effects should be understood are similar for the two variables. Higher scores on the political variables imply that political leaders and other key stakeholders have invested considerable human and financial resources, as well as political capital, in order to improve the leadership and human rights qualities of the response. However, a politician will only be rewarded politically in the media or in the next electoral campaign for making such investments if it can be shown that they have had a positive effect. And such evidence can only be generated through effective M\&E. The same logic applies to the human rights qualities of the response. Political leadership and other country stakeholders who invest resources in ensuring that human rights are respected in the response will want to monitor that their commitment to human rights actually determine the overall implementation of the response.

It is interesting to note that strong political support also has a causal effect on the quality of the human rights mainstreaming of the response. This would suggest that strong political leadership generates two concrete effects: effective human rights mainstreaming and strong M\&E. In terms of identifying the first causal factor in our pathway, the critical question then becomes what political factors can explain why leaders in some countries show stronger support for the AIDS response. Of all the political variables we have worked with in this analysis, it is only the governance index that has a causal effect on 'political support'. None of the control variables had any significant effect. The level of political support shown by leaders does not depend on levels of 
domestic finances or foreign aid for AIDS, it does not depend on ethnic fractionalisation or even on the severity of the epidemic. The determinant of strong political support is the quality of governance in the state more generally. Good governance has a direct effect on policy outcomes, but it further improves the response by generating strong political support, which in turn strengthens the response through more programmatic interventions.

\section{Conclusions}

Our analyses have generated four main results. The first is the strong suggestion in the data that good governance more generally in the state is the most important political determinant of effective policy outcomes. Effective responses to AIDS across the sub-Sahara African countries are not caused by political mobilisation, the available financial resources or by the scale of the epidemic. Instead, countries achieve better coverage of ART because they are less corrupt, because their governments and public administrations are more effective, because financial transactions are better regulated and because the polity has more respect for the rule of law. In order to improve treatment coverage these countries may not need more money as much as they need better bureaucrats. The second result suggests that the quality of governance in the AIDS response itself has an effect on policy outcomes. The API data suggest that a successfully adapted international blueprint will help generate better policy outcomes. However, our explorative pathway analysis showed that effective AIDS governance is at least in part an effect of good governance more generally. This finding reinforces the suggestion that good governance is the fundamental explanation for successful policy outcomes.

The third finding is more problematic for advocacy. The fact that none of the political variables that capture democratic elements of political rights, electoral accountability or political competitiveness even correlate with AIDS policy outcomes would seem to undermine the opportunity for effective advocacy in the political arena. If any of these variables would have had a causal effect on outcomes, such a link would immediately have suggested strategic opportunities for advocacy. And yet, policy advocates have no other arena in which to act. Although these statistics suggest it would make a difference, AIDS activism would probably soon lose momentum if the rallying call was 'more ARVs, less corruption!' The fourth main finding may, however, suggest an alternative strategy.

The fact that both governance and democracy had a causal effect on the child-specific but nonstigmatised policies of schooling and immunisation may hold clues for advocacy for better policy responses to the needs of children affected by AIDS. While access to water and sanitation are insensitive to qualitative aspects of the political regime, the level of coverage of the child-specific policies are better in countries where the children's parents are part of a more empowered and politically effective constituency. However, in order for the need for such services from the state to become a political incentive for government action, individual needs must be mobilised and aggregated into demands from a constituency. But this mobilisation is of course much more difficult when the need is as stigmatised as AIDS.

The statistical results and our reasoning around incentives for political mobilisation and government action suggest that interventions aimed at benefiting children affected by HIV/AIDS should be part of a set of welfare policies that are AIDS sensitive in character but universal in application. Only with such a political framing of the issues can demands be freed of stigma and the supply become part of a political contract that governments default from only at great political cost. Only then will politics in Africa really work for the benefit of children affected by AIDS.

\section{Notes}

* We wish to thank colleagues in the the Joint Learning Initiative on Children and HIV/AIDS (JLICA) network, and especially Alex de Waal, for comments on earlier drafts of this article. Comments are welcome to Per.Strand@uct.ac.za

1 The expanded version of the article will be available as a CSSR Working Paper and can be

downloaded from the CSSR website at: www.commerce.uct.ac.za/Research_Units/CSSR/ pubs_cssr_display.asp, or it can be requested from Per Strand.

2 See www.freedomhouse.org

3 See www.systemicpeace.org/polity/polity4.htm

4 The three regressions on 'school' explained some 32-8 per cent of the variation (adjusted $R^{2}$ ), with 
GPD per capita being the strongest variable. In the three regressions on 'immunisation', explaining some 29-32 per cent of the variation, the variable

\section{References}

Bor, Jacob (2007) 'The Political Economy of AIDS Leadership in Developing Countries: An Exploratory Analysis', Social Science and Medicine 64: 1585-99

Goetz, Anne Marie and Jenkins, Rob (2004) Reinventing Accountability: Making Democracy Work for Human Development, London: Palgrave Macmillan

Halperin, Morton H.; Siegle, Joseph T. and Weinstein, Michael M. (2005) The Democracy Advantage: How Democracies Promote Prosperity and Peace, New York: Routledge

Kauffman, D.; Kraay, A. and Mastruzzi, M. (2004) 'Governance Matters III: Governance Indicators for 1996, 1998, 2000, and 2002', The World Bank Economic Review 18.2: 253-87

Kinney, Mary (2007) The Impact of Foreign Aid on the HIV/AIDS Epidemic in Africa, Political Studies, Cape Town: University of Cape Town

Lieberman, Evan S. (2007) 'Ethnic Politics, Risk, and Policy-Making: A Cross-National Statistical Analysis of Government Responses to HIV/AIDS', Comparative Political Studies 40.12: 1407-32

Lindberg, Staffan I. (2006) Democracy and Elections in Africa, Baltimore: Johns Hopkins University Press

Monasch, Roeland; Stover, John; Loudon, M.; Kabira, D. and Walker, N. (2007) 'National Responses to Orphans and Other Vulnerable Children in Sub-Saharan Africa: The OVC Policy and Planning Effort Index, 2004', Vulnerable Children and Youth Studies 2.1: 40-59

Nattrass, Nicoli (2006) 'What Determines CrossCountry Access to Antiretroviral Treatment?', Development Policy Review 24.3: 321-37

POLICY Project (2003) The Level of Effort in the National Response to HIV/AIDS: The AIDS on foreign aid ('total ODA'), was the strongest predictor. The political variables were the only other significant variables in each regression.

Programme Effort Index (API) 2003 Round, Washington DC: USAID, UNAIDS, World Health Organization (WHO), POLICY Project

Posner, Daniel N. (2004) 'Measuring Ethnic Fractionalization in Africa', American Journal of Political Science 48.4: 849-63

Sen, Amartya (1999) Development as Freedom, New York: Random House

Strand, Per (2007) 'Comparing AIDS Governance: A Research Agenda on Responses to the AIDS Epidemic', in N.K. Poku, A. Whiteside and B. Sandkjaer (eds), AIDS and Governance, Aldershot: Ashgate

UNAIDS (2008) Children and AIDS: Second Stocktaking Report, Geneva and New York: UNAIDS, UNICEF, World Health Organization (WHO)

UNAIDS (2007) Children and AIDS: A Stocktaking Report, Geneva and New York: UNAIDS, UNICEF, WHO

UNAIDS (2006a) International Guidelines on HIV/AIDS and Human Rights, 2006 Consolidated Version, Geneva: UNAIDS

UNAIDS (2006b) Report on the Global AIDS Epidemic, Geneva: UNAIDS

UNAIDS (2004) 'Three Ones' Key Principles: Coordination of National Responses to HIV/AIDS, Geneva: UNAIDS

UNDP (2006) Human Development Report 2006. Beyond Scarcity: Power, Poverty and the Global Water Crisis, New York: United Nations Development Programme (UNDP)

UNDP (2002) Human Development Report: Deepening Democracy in a Fragmented World, Oxford: Oxford University Press 